\section{ESPACIO PÚBLICO, PERIFERIA URBANA Y DERECHO A LA CIUDAD. INTERVENCIÓN PARQUE CARACOLÍ, CIUDAD BOLÍVAR*}

Sandra Caquimbo Salazar**, Olga Lucía Ceballos Ramos***, Cecilia López Pérez****

\section{Resumen}

La informalidad en la producción del hábitat continúa avanzando en las ciudades colombianas con una característica común: la ausencia de espacio público que facilite la vida en comunidad. En momentos en los que se reivindica el derecho a la ciudad, las acciones gubernamentales parecen ser insuficientes. Aparece entonces una reflexión para la academia sobre la posibilidad de empoderar a los habitantes de los barrios populares para intervenir de manera efectiva en la transformación de su realidad. Desde esa perspectiva se presenta una experiencia desarrollada en el barrio Caracolí, un asentamiento de origen informal en Bogotá D.C., Colombia, donde se articularon objetivos académicos y sociales mediante el mejoramiento de las condiciones físicas del único parque existente allí.

\section{PUBLIC SPACE, PERI-URBAN AREAS AND THE RIGHT TO THE CITY. INTERVENTION IN CARACOLÍ PARK, CIUDAD BOLÍVAR*}

Sandra Caquimbo Salazar**, Olga Lucía Ceballos Ramos***, Cecilia López Pérez $^{* * * *}$

\section{Abstract}

The informal production of habitat is a growing phenomenon in Colombian cities, which share a common characteristic: the lack of public space to enable the development of community life. In a period when the right to the city has been reclaimed government actions seem to be insufficient. There is then a reflection for academics to empower the inhabitants of popular neighborhoods to effectively influence the transformation of their realities. From this perspective, this paper presents the work conducted in Caracoli, an informal settlement located in Bogotá DC, Colombia, where different academic and social objectives were combined to improve the physical conditions of the only 
Se exponen así los antecedentes teóricos, junto con resultados de investigaciones precedentes desarrolladas por las autoras, y el desarrollo de la actividad, para concluir sobre la necesidad de articular saberes en torno a la acción para la construcción de comunidad y de ciudad.

\section{PALABRAS CLAVE: ESPACIO PÚBLICO; PERIFERIA URBANA; METODOLOGÍAS PARTICIPATIVAS; CIUDAD BOLIVAR-BOGOTÁ D.C.}

Recibido: 23-09-2015

Aceptado: 04-10-2016

* Artículo elaborado con base en resultados de investigaciones realizadas por las autoras, en el contexto colombiano con financiación de la Pontificia Universidad Javeriana, sobre temáticas relacionadas con asentamientos informales y espacio público. Asimismo, de una experiencia docente conjunta aplicada en un espacio público localizado en el barrio Caracolí, asentamiento de origen informal, en la ciudad de Bogotá D.C.

* Colombia. Arquitecta, Universidad Nacional de Colombia; Magíster en Paisaje, Medio Ambiente y Ciudad, Universidad Nacional de La Plata, Argentina; Especialista en Vivienda Social, Universidad de Chile. Profesora asistente de la Pontificia Universidad Javeriana, Facultad de Arquitectura y Diseño, miembro del Grupo de Investigación Calidad y Habitabilidad de la Vivienda y Coordinadora editorial de Cuadernos de Vivienda y Urbanismo. Correo electrónico: scaquimbo@javeriana.edu.co

** Colombia. Arquitecta, Magíster en Urbanismo, Universidad Nacional de Colombia. Profesora asociada de la Pontificia Universidad Javeriana, Facultad de Arquitectura y Diseño. Líder del Grupo de Investigación Calidad y Habitabilidad de la Vivienda y Directora editora de Cuadernos de Vivienda y Urbanismo. Correo electrónico: olga.ceballos@javeriana.edu.co

**** Colombia. Arquitecta, Magíster en Restauración de Monumentos Arquitectónicos, Pontificia Universidad Javeriana. Candidata a doctora en Ingeniería de la Universidad Tecnológica de Panamá. Profesora asistente de la Pontificia Universidad Javeriana, Facultad de Arquitectura y Diseño. Líder del grupo de investigación GRIME. Correo electrónico: lopez.c@javeriana.edu.co park in the area. This study shows theoretical backgrounds, the results of previous research developed by the authors and the development of activities to conclude on the need to combine different knowledge for the construction of communities and cities.

\section{KEYWORDS: PUBLIC SPACE; PERI-URBAN AREAS; PARTICIPATORY METHODOLOGIES; BOLIVAR- BOGOTÁ DC.}

Received: 23-09-2015

Accepted: 04-10-2016

* Funded by Javeriana University, this paper is based on the results of re search conducted within the Colombian context of informal settlements and public space and a joint teaching experience in Carcolí, Bogotá DC.

* Colombia. Architect, National University of Colombia; MSc in Landscape Environment and City, National University of La Plata, Argentina; Specialist in Social Housing, University of Chile. Assistant professor, Javeriana University, Faculty of Architecture and Design,-member of the Research Group on Housing Quality and Habitability. Coordinator, Cuadernos de Vivienda y Urbanismo. Email: scaquimbo@javeriana.edu.co

** Colombia. Architect, MSc in Urban Development, National University of Colombia. Associate professor, Javeriana University, Faculty of Architecture and Design. Head of the Research Group on Housing Quality and Habitability. Director, Cuadernos de Vivienda y Urbanismo. Email: olga. ceballos@javeriana.edu.co

**** Colombia. Architect. MSc in Restoration of Architectural Monuments, Javeriana University. PhD student in Engineering, Panama University of Technology. Assistant professor, Javeriana University, Faculty of Architecture and Design. Head of the GRIME research group.Email: lopez.c@ javeriana.edu.co 


\section{Introducción}

La conformación de asentamientos informales ${ }^{1}$ constituye un fenómeno aun presente en la ciudad colombiana dados los niveles de pobreza en el país y el avance de un conflicto armado interno que supera ya cinco décadas. Frente a esta situación, Bogotá ha tenido un alto impacto con la recepción de la mayor cantidad de población desplazada: 540.714 personas entre 1992 y 2012 2 . El esfuerzo de las administraciones de la ciudad ha sido insuficiente ante el acelerado avance de la informalidad. "La cantidad de ocupaciones ilegales continúa siendo una situación preocupante, pues aun cuando en 2014 tuvo un aumento inferior al 10\% respecto al año anterior, con 1.280 unidades nuevas, esta problemática sigue constituyendo una demanda importante para las políticas de hábitat de la ciudad" (ver figura 1)3. Dichos asentamientos, además de localizarse en la periferia de la ciudad, ocupan terrenos con problemáticas como mala calidad del suelo, condiciones de riesgo por deslizamiento o inundación, dificultades de conexión con la ciudad y son altamente deficitarios de servicios urbanos ${ }^{4}$. Esta situación es particularmente preocupante en la Localidad de

1 Se denomina asentamientos urbanos informales a los realizados sin el cumplimiento de las normas urbanísticas. También conocidos como barrios populares.

2 CODHES, s.f.

3 Ceballos, Vega, Férnandez, Martínez, Ferney, Landond, Chaparro, Caicedo, Rincón y Giraldo, 2015.

4 Tarchópulos y Ceballos, 2005.
Ciudad Bolívar ${ }^{5}$, donde la cantidad de ocupaciones ilegales ha sido mayor que en el resto de la ciudad y continúa incrementándose (ver figura 2), haciendo evidente que la ciudad informal ${ }^{6}$ es la manera en la que finalmente los más pobres logran acceder a su derecho a la ciudad y a la vivienda, cuando las políticas públicas no les permiten un acceso efectivo a estos derechos.

En este contexto, el artículo describe una experiencia pedagógica y teórico-práctica, asociada a resultados de investigaciones precedentes realizadas por las autoras, desarrollada en busca de metodologías de intervención en barrios populares que, desde la academia, permitan empoderar a sus habitantes para la reivindicación de sus derechos. Dicha experiencia consistió en intervenir el parque del barrio Caracolí (Localidad de Ciudad Bolívar), realizada con estudiantes de la Facultad de Arquitectura y Diseño, de la Pontificia Universidad Javeriana. De ella se expone el proceso de trabajo en campo y en aulas, que permitió identificar las necesidades, afectaciones y vocación del lugar; el cual produjo un diagnóstico que sirvió de base para el desarrollo de los diseños, programar

5 Bogotá está dividida administrativamente en 20 localidades.

6 Se denomina "ciudad informal" a la que se conforma a partir de los asentamientos urbanos informales. 
FIGURA 1. OCUPACIONES ILEGALES 2009-2014

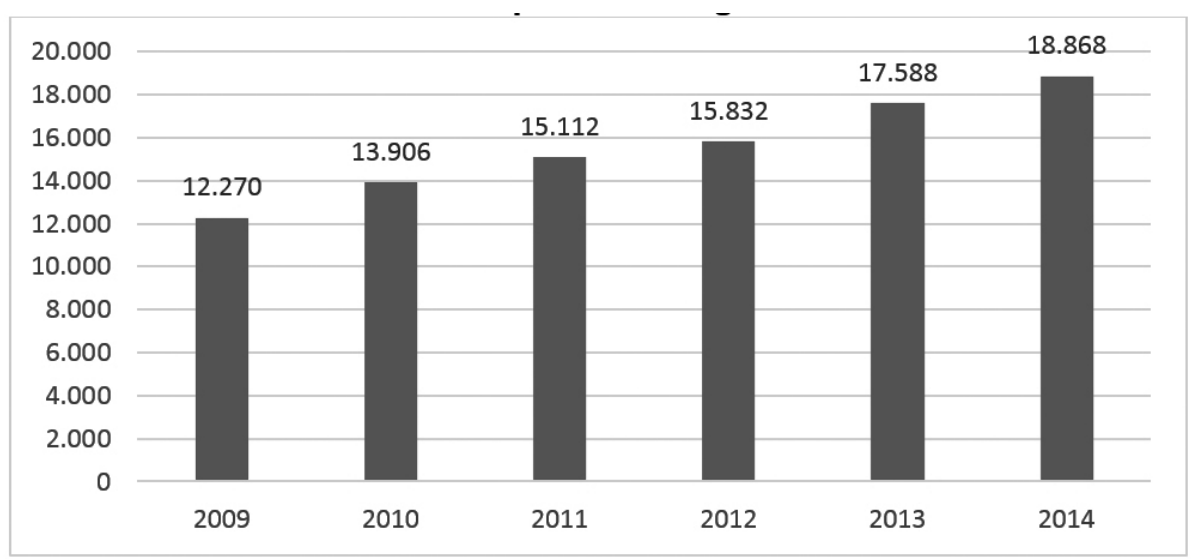

Fuente: Secretaría Distrital del Hábitat, 2015

\section{FIGURA 2. OCUPACIONES ILEGALES SEGÚN LOCALIDAD 2009-2014}

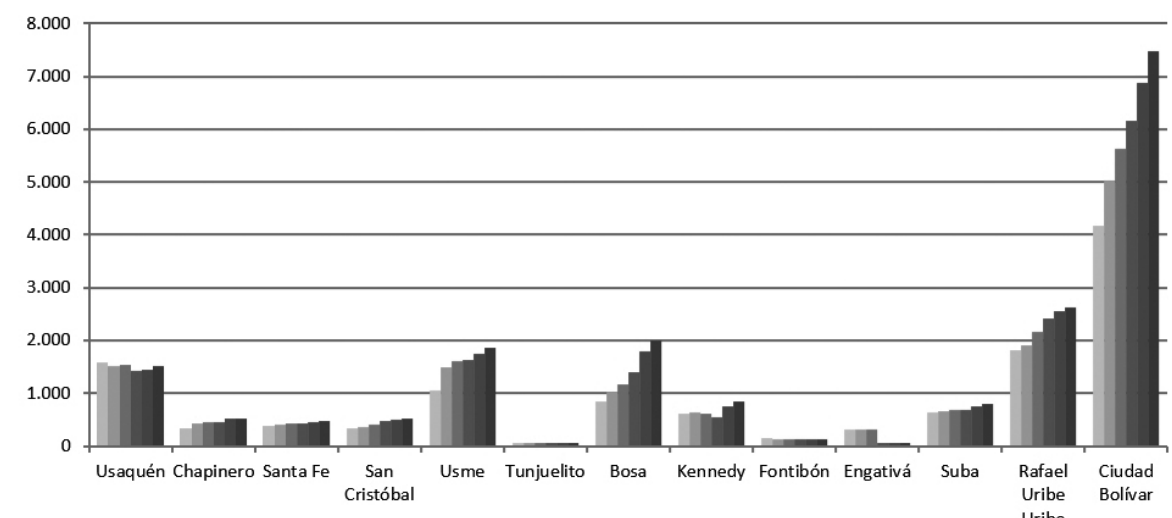

Fuente: Elaboración propia con datos de Secretaría Distrital del Hábitat, 2015. 
actividades con los estudiantes, la comunidad y grupos de apoyo; así como, la gestión de recursos para la construcción.

\section{El espacio público en los asentamientos informales}

Una característica común en los asentamientos informales es la ausencia de un espacio público que facilite la vida en comunidad, lo cual se explica desde su origen ligado a procesos urbanos al margen de las disposiciones urbanísticas. En este contexto, el derecho a la ciudad queda subordinado a la definición de las áreas privadas de vivienda, asociada en muchos casos al logro de la mayor rentabilidad posible ${ }^{7}$ mediante el uso intensivo del suelo. Si bien, lo anterior no es exclusivo de los desarrollos urbanos informales, es más dramático en estos asentamientos por cuanto desde su origen existe un desconocimiento de lo público. Sus promotores basan su rentabilidad en dos condiciones:

7 En Colombia buena parte de los asentamientos informales se han sido producido a partir de procesos de Urbanización Pirata. A diferencia de otros países latinoamericanos, se trata principalmente de dos tipos de promoción urbana: uno que actúa por encargo del propietario de la tierra a urbanizadores informales (también llamados piratas o tierreros) y otro por acción directa de dichos agentes mediante la invasión de predios privados 0 públicos para su comercialización. El suelo puede ser rural, de reserva o no apto para la urbanización por condiciones de riesgo no mitigables. (Ver Torres, 2009). el aprovechamiento de una plusvalía generada por su decisión de pasar de un suelo rústico o no urbanizable a un uso urbano, sin retribución alguna para la ciudad, y la no destinación de áreas para espacio público ${ }^{8}$.

En el caso de Bogotá, varios estudios sobre la espacialidad en la periferia urbana dan cuenta de un desarrollo urbano deficitario, tanto en barrios de origen informal como en el formal ${ }^{9}$. La situación de mala calidad de la vivienda, en la escala arquitectónica en ninguna medida se ve compensada por el espacio público. El poco del que se dispone en los asentamientos informales, se caracteriza además de su escasez, por lo inhóspito. Generalmente se trata del peor suelo, el menos aprovechable, el "sobrante" de lo explotable. Así, se convierte en muchos casos en el espacio de la segregación social, la desconfianza, el territorio del miedo, donde las comunidades deben luchar durante mucho tiempo, y no siempre con éxito, para el logro de un cambio $^{10}$. Son circunstancias que finalmente redundan en desarraigo, en el "desarrollo exclusivis-

\footnotetext{
8 Tarchópulos y Ceballos, 2005.

9 Tarchópulos y Ceballos, 2003, 2005.

10 Ceballos, 2008.
} 
ta y excluyente de apropiación del espacio público"11. En este sentido, la mala calidad del espacio físico propicia una percepción de inseguridad que empuja al abandono de lo público, de lo colectivo, lo que a su vez deriva en la pérdida de interés por el intercambio social, por la comprensión y respeto del "otro". Dicho abandono acentúa el deterioro progresivo del espacio y, en consecuencia, dificulta el desarrollo de vínculo con el territorio (sentido de pertenencia) y la construcción de comunidad ${ }^{12}$.

No obstante, "el espacio público en los barrios populares, al igual que la vivienda, es en gran medida producido y transformado por los mismos habitantes. De la misma forma, estos espacios son principalmente usados por la gente que vive alrededor, con pocos 'forasteros' o visitantes haciendo uso de ellos. La materialidad observada entonces, puede decirse que corresponde largamente a las necesidades, expectativas, posibilidades y construcciones simbólicas de los habitantes de los barrios. Las prácticas sociales se transforman para acomodarse a las interacciones con el espacio público, mientras que el espacio cambia para acomodarse a esas nuevas y cambiantes interacciones sociales"13.

Pero la situación presente en los asentamientos informales, específicamente en lo que respecta al

\footnotetext{
Jaramillo, 1998, p. 22.

Caquimbo, 2008.

Hernández, 2013.
}

118 revista invi 32(89) : 113-143, mayo 2017 espacio público, llama la atención en momentos en los que se reivindica el derecho a la ciudad frente a lo cual las acciones gubernamentales parecen ser erradas o al menos insuficientes. La realidad en muchos asentamientos informales sigue siendo dramática en términos de ausencia no solo de espacio público, sino igualmente de construcción de comunidad y sin perspectiva de cambio, al menos en el corto plazo. Esta problemática se ha acentuado además por los procesos también "informales" de densificación, donde aún no se supera su situación de déficit inicial de espacio público. La escasez de suelo urbanizable y un déficit cuantitativo de vivienda que no logra superarse, especialmente el de la población de menores ingresos, ha incentivado una oferta de "vivienda multifamiliar informal" que está reproduciendo y agravando las deficiencias de calidad detectadas años atrás ${ }^{14}$.

Actualmente, las comunidades están recibiendo el impacto que generan estos procesos, desprotegidas y con autismo por parte de las autoridades de planeación de la ciudad, al igual que con poca capacidad de reacción ante este fenómeno por parte de las autoridades locales. Entre tanto, el debate sobre el futuro próximo de Bogotá avanza entre teóricos, políticos y técnicos, respecto a las ventajas

14 Información verificada en el trabajo de campo en la asignatura de segundo ciclo de arquitectura Proyecto Vivienda Popular PVP, desde el año 2010. Facultad de Arquitectura y Diseño. Pontificia Universidad Javeriana. 
o desventajas de densificar o expandir la ciudad. Los habitantes residentes en los barrios de origen informal están como siempre ajenos al debate, aún sometidos a unas condiciones de habitabilidad muy deficitarias, en las cuales el espacio público continúa jugando en su contra ${ }^{15}$.

En este contexto, cabe preguntarse sobre las opciones que tienen los ciudadanos de los barrios populares para reivindicar su derecho a una ciudad amable que dignifique su existencia. Los canales de participación en el planeamiento urbano les resultan esquivos por cuanto la planeación macro de alguna manera invisibiliza lo que la cotidianidad denota. Los habitantes de los barrios populares, son conscientes de la importancia que tiene para sus vidas el contar con espacios de recreación y esparcimiento cerca a sus viviendas, saben asociar la disminución de factores de violencia cuando los jóvenes tienen lugares para practicar deportes y los niños pueden jugar sin estar sometidos a situaciones de riesgo social.

15 Aun cuando numerosos estudios han confirmado la correlación entre enfermedades crónicas y la ausencia de espacio público, en Bogotá continúa siendo un tema secundario. (Ceballos, Caicedo, Fernández y Rincón, 2014; Ceballos, Vega, Fernández, Martínez, Ferney, Londoño, Chaparro, Caicedo, Rincón y Giraldo, 2015).

\section{La participación como marco conceptual para la reivindicación del espacio público}

En la reflexión en torno a la reivindicación el derecho a la ciudad a través del espacio público, surge la iniciativa de una acción de mejoramiento en asentamientos informales que conllevó, a su vez, a una aproximación conceptual situada en el marco de las metodologías participativas, con énfasis en la articulación de saberes, dado que se entiende por participación "aquellas iniciativas sociales en las que las personas toman parte consciente en un espacio, posicionándose y sumándose a ciertos grupos para llevar a cabo determinadas causas que dependen para su realización en la práctica, del manejo de estructuras sociales de poder"16.

Al respecto, desde hace décadas se han explorado metodologías donde la participación juega un rol fundamental. A principios del siglo XX Walter Gropius, en la Bauhaus, desarrolló un modelo educativo que integraba saberes a partir de la idea del trabajo colaborativo. Con esta iniciativa se avanzó

16 Mujeres y género en América Latina, sf. 
en la integración disciplinar en pro de una construcción más compleja del conocimiento, pero se mantuvo el dominio del saber "experto". Posteriormente, en los años cuarenta del mismo siglo, desde lógicas hoy conocidas como bottom-up (de abajo hacia arriba), y en la búsqueda de la autonomía de las comunidades para el trabajo colectivo en torno al mejoramiento de su hábitat, aparece la investigación-acción, que se entiende como un proceso que evoluciona de forma sistémica cambiando, tanto para quien cumple las funciones de investigador, como en las situaciones en las que actúa. La acción, por su parte, es en donde se pone de manifiesto el actuar, el movimiento de una comunidad en hechos concretos; y finalmente, la participación como la acción social respecto a un asunto que implica relación con otras personas ${ }^{17}$.

En este marco, en las décadas del 60 y el 70, arquitectos como C. Alexander, J. Turner y N.J. Habraken, trabajaron métodos que proponen la participación como elemento esencial para el proceso de diseño. Y es durante de este periodo, cuando

17 Bocanegra, 2015. se plantea el concepto de investigación acción participativa (IAP), reconocida como una metodología que desafía la concepción tradicional de ciencia en la búsqueda de romper con la oposición teoría práctica $^{18}$, articula ambas formas de conocimiento en la acción social. De igual manera, la oposición entre sujeto que conoce y objeto de investigación, pretende avanzar en el logro de consensos que demanda un trabajo en el cual se reconozca y se respete a la comunidad participante aun cuando no forme parte de un ámbito académico ${ }^{19}$. Por lo tanto, el primer paso aquí es reconocer una demanda social, a partir de la cual sea posible plantear un proyecto basado en la negociación con los sectores o instituciones demandantes. En este sentido, el diagnóstico y la propuesta deben comunicarse de manera clara ante la totalidad de los actores de manera que sea posible la interacción real de todos los involucrados, dando como resultado un trabajo colaborativo: "La prueba de la validez de la investigación-acción no es su aceptación por una comunidad de investigadores expertos, sino que se juzga entre los duenos locales del problema en cada situación específica.

18 "La Investigación - Acción Participativa (IAP) es un método de investigación cualitativa, que aspira generar conocimiento de interés social y transformar la realidad que constituye el objeto de estudio. En este proceso, los actores sociales se consideran partícipes de la acción y del conocimiento generado, y no meramente informantes, dado que a partir del diagnóstico se generan propuestas que son llevadas a la práctica en conjunto con todos los sectores interesados" (Varisco, Benseny, Castelluci, González, Padilla, Muñoz y César, 2015, p. 3).

19 Ortiz y Borjas, 2008 
Si tienen suficiente confianza en los resultados para tomarse el riesgo personal y social de actuar de acuerdo con ellos, se considera un resultado válido"20.

En Colombia, específicamente en Medellín y Bogotá ${ }^{1}$, se retomó el modelo de ciudad creativa planteado por Charles Landry y Franco Bianchini en la década del 80, Este modelo se basa en el supuesto de que la creatividad es el recurso fundamental para solucionar los problemas urbanos. En ellas, se congregan distintos sectores para generar un cambio social y beneficios a largo plazo para sus habitantes. La intervención pública se hace en el ámbito cultural, fundamentado en la reconstrucción de la confianza entre vecinos, conciudadanos y respeto a las autoridades. En la década del 90, en América Latina, el programa CYTED ${ }^{22}$ adelantó, desde el subprograma Habyted, investigaciones en torno al tema del diseño y la planificación participativa en el marco de la producción social del hábitat.

Así, las metodologías participativas en el país han sido ampliamente empleadas con varios ejemplos exitosos de intervención. En Bogotá, durante la primera administración de Antanas Mockus, se desarrolló el programa "Obras con saldo pedagógico", basado en una metodología de planeación y gestión participativa a escala zonal. Desde el

20 Greenwood, 2000, p. 34.

21 Duarte, Salinas, Cornejo, Olave y Katz, 2013.

22 Programa iberoamericano de ciencia y tecnología para el desarrollo. programa se convocó a las organizaciones comunitarias de barrios de desarrollo incompleto, localizados en diferentes zonas de la ciudad, para concursar por recursos destinados al mejoramiento del espacio público. Las organizaciones que participaban, competían en igualdad de condiciones, pero se valoraba principalmente el nivel de organización y de participación de la comunidad. Como otros criterios de selección de las propuestas, se tenía su calidad y sostenibilidad, con el interés de garantizar que las ganadoras correspondieran al esfuerzo y la iniciativa de las comunidades involucradas. De esta manera, se consideraba que era posible lograr mayor apropiación del espacio público intervenido por parte de los ciudadanos. Aun cuando no se registran datos precisos sobre la cantidad total de obras financiadas en el marco de este programa, aparentemente sumaron cerca de mil intervenciones ${ }^{23}$.

Con respecto a sectores informales de la ciudad, en 2002 la oficina de Gestión para la Sostenibilidad Social, Económica y Ambiental adquirió el Parque Illimani - Ciudad Bolívar, emprendiendo una gestión social que buscaba la participación de la comunidad en un $70 \%$ de la construcción del parque a través de mano de obra del sector, especialmente

23 Obras con Saldo Pedagógico (Colombia), 2000. 
de los barrios Arborizadora Alta, Mirador, El Edén, Paraíso San Francisco y Bella Flor ${ }^{24}$. De forma paralela, en todas las actividades relacionadas con el parque se vincularon niños y jóvenes convirtiéndolos en actores activos de la supervivencia y mantenimiento del lugar. Otros ejemplos en la ciudad son el del "Parque Diana Turbay-Cultivos", realizado en el 2005, en el barrio Diana Turbay de la localidad de Rafael Uribe. El proyecto consistía en un parque vecinal que incluía juegos infantiles y un sendero peatonal que comunica el barrio Diana Turbay con los barrios La Marquesa, San Ignacio y la Serranía ${ }^{25}$. Y en el 2006, en la localidad de Engativá, el proyecto de parque y vía "Senderos de vida", presentado por la Junta de Acción comunal, el cual consistía en el mejoramiento de las áreas aledañas a una cancha múltiple, en un área residencial ${ }^{26}$.

Recientemente se han retomado los enfoques del trabajo colaborativo vinculado a la participación social, dando origen a diversas iniciativas como las wikis, los crowdsourcing, o la edición colaborativa, que según Martin-Iglesias ${ }^{27}$ es adoptada tanto para la producción de textos como para el desarrollo de programas o lenguajes de programación (código abierto). Así, en su mayoría, estas nuevas iniciativas tienen un fuerte soporte tecnológico y

24 Hernández, 2008.

25 ibíd.

26 Niño y Chaparro, 1997.

27 Martin-Iglesias, 2011.

122 revista invi 32(89) : 113-143, mayo 2017 han sido orientadas hacia las áreas de la educación, la informática, y el diseño industrial.

Por otra parte, en la arquitectura y el diseño urbano se ha continuado también el trabajo desde esta perspectiva, encontrándose conceptos como el de Beta permanente que "hace alusión a la reivindicación del proceso frente al objeto -lógica procesual frente a lógica objetual-, a la horizontalidad del trabajo y al pensamiento en red (network thinking), al desarrollo de la inteligencia social y colectiva, a la apropiación comunitaria de los proyectos, a la colaboración y a las redes de apoyo mutuo"28. Con este concepto, se plantea la intervención urbana como un proceso no terminado, donde se establecen puntos de partida, horizontes de posibilidades y las decisiones clave son tomadas en colectivo. Una de las etapas de este proceso, en la que la participación resulta esencial para la toma colectiva de decisiones, es el diseño. Al respecto, y desde la teoría de juegos, el Diseño Colaborativo aparece como metodología que propicia el desarrollo de procesos de decisión no jerarquizados, donde la creación conjunta entre actores heterogéneos que trabajan en torno a metas comunes, aprovecha la inteligencia colectiva para lograr diseños innovadores y adecuados a cada situación particular ${ }^{29}$.

28 Acero, Aguirre, Arévalo, Díaz y Romero, 2012, p. 20-21.

29 Ibíd. 
En este sentido, y en relación específica con el espacio público, Trachana ${ }^{30}$ propone que el soporte tecnológico actual permite una concepción diferente de éste, a partir de la experiencia, de la subjetividad. Una aproximación que transforma la manera en que se comprende, se imagina y se demanda espacio público en la ciudad contemporánea, ya no desde la morfología del espacio sino desde el acontecimiento que él contiene. Al respecto, a partir de la revisión de recientes iniciativas de intervención en espacios públicos, la autora señala que "las formas más positivas de intervención pasan necesariamente por procesos que implican la participación de la inteligencia local en diálogo con saberes interdisciplinares (...). Hoy, más que nunca, podemos decir que no es tanto lo nuevo lo que se necesita, sino más bien, agregar valor a lo existente al transformarlo potenciando sus características propias, inventando nuevas posibilidades de apropiación" 31 .

Ante estos antecedentes, y considerando la problemática expuesta en relación con el espacio público en asentamientos informales, se planteó como hipótesis de trabajo que la academia puede contribuir a empoderar a los habitantes de los barrios populares para intervenir de manera efectiva en la transformación de su realidad. Lo anterior, sin suplir la responsabilidad que compete directamente al Estado sobre lo público, pero procurando paliar el apremio de las dificultades de los habitantes, con los medios que estén a su alcance, sin renunciar de esta manera a la reivindicación de sus derechos ciudadanos. De igual forma, con respecto a las posibilidades de generar capacidades de gestión sobre el territorio por parte de las comunidades a fin de que pueda lograrse coherencia entre los procesos sociales y la transformación espacial. Así se plantea también la necesidad de recurrir a estrategias metodológicas que favorezcan el diálogo entre saberes distintos pero orientados al logro de un objetivo común, en este caso, el mejoramiento de condiciones de vida de los habitantes de estos barrios. Por lo tanto, metodologías de trabajo como las presentadas, dadas sus características y buenos resultados en experiencias previas, pueden aportar al desarrollo de la reflexión planteada.

\section{Aproximación a una experiencia de intervención. Una propuesta metodológica}

El proceso de formación de arquitectos en Colombia, tradicionalmente ha privilegiado los aspectos relacionados con la producción formal de la ciudad, en tanto que la comprensión de la informal

\section{Trachana, 2013.}

31 Trachana, 2013, p. 48-49. 
ocupa un segundo plano. No obstante, la realidad de la ciudad colombiana ha sido construida en su mayoría por la informalidad, rasgo que comparte con muchas ciudades latinoamericanas. Bajo esta idea, la articulación del conocimiento generado a través de investigaciones realizadas por las autoras de este artículo, con la formación de nuevos arquitectos se ha posibilitado desde la asignatura Proyecto de Vivienda Popular PVP, correspondiente al segundo ciclo de la carrera de arquitectura en la Pontificia Universidad Javeriana - PUJ, en una propuesta pedagógica donde se enlazan miradas desde lo estético, lo social, lo tecno ambiental, lo urbano y la gestión, con el diseño. Este escenario académico ha permitido abordar la reflexión del cómo intervenir en tejidos urbanos con problemáticas sociales tan complejas como las presentes en los barrios informales. Así, desde 2011 esta experiencia académica se ha vinculado al trabajo de dos programas sociales de la PUJ, uno de ellos denominado VIDAS MÓVILES, creado con el objetivo de acompañar, orientar y atender de manera integral a población en situación de desplazamiento forzado y a población en condiciones de vulnerabilidad ubicadas en la localidad de Ciudad Bolívar, Bogotá, D.C.

En este marco, en el segundo semestre de 2013, con la complicidad de algunos amigos profesores de la Facultad de Arquitectura de la Universidad de Costa Rica UCR y del colectivo también costarricense PAUSA URBANA, se decidió realizar una experiencia complementaria desde el PVP en los barrios de estudio, con el ánimo de generar procesos de actuación desde las comunidades frente al espacio público. La experiencia que interesa presentar en este escrito se desarrolló específicamente en el barrio Caracolí, barrio de origen informal ubicado en la localidad de Ciudad Bolívar, en Bogotá D.C. En este barrio, habitan familias compuestas en un alto porcentaje por niños y adolescentes, que viven en condiciones de pobreza y pobreza extrema, cuyos miembros en muchos casos han sido desplazados víctimas del conflicto armado interno del país o desmovilizados y reinsertados del mismo conflicto.

El recorrido por el barrio denotaba que en general la condición física de los espacios públicos no favorecía, precisamente, el encuentro ni incentivaba su uso por parte de los habitantes. Además de ser muy escasos y pequeños, presentaban condición de alto deterioro. Su uso era restringido, pues existía una problemática social derivada principalmente del microtráfico de sustancias sicoactivas que llevaban al enfrentamiento en estos espacios entre pandillas de jóvenes vinculados a este mercado ilegal, al igual que al encuentro de consumidores de esas sustancias. Esto, impedía que otros miembros de la comunidad residente pudieran disfrutar del espacio público para actividades de esparcimiento o de tipo cultural. 
Las circunstancias descritas, condujeron a proponer el desarrollo de una acción física sobre el único parque del barrio, en busca de tres objetivos fundamentales: a) desarrollar una intervención en un espacio público deteriorado y con baja apropiación por parte de la comunidad en el barrio Caracolí, que permitiera mejorar su funcionalidad y generar nuevas actividades contribuyendo a una mejor vida comunitaria; b) realizar un trabajo CON la comunidad que los impulsara a empoderarse de su territorio, asumiendo acciones futuras de manera autónoma; y c) generar un espacio de aprendizaje multidimensional para estudiantes y profesores, a partir del trabajo mancomunado con los habitantes del barrio.

Para el logro de estos objetivos, y de acuerdo con las metodologías participativas revisadas, se resolvió desarrollar la experiencia retomando como principios: el diálogo de saberes; la participación de la comunidad, el trabajo colaborativo; y la valoración de lo existente y de la experiencia, como vivencia presente y deseada. En este contexto, y de acuerdo con Trachana ${ }^{32}$, la acción a emprender sería una intervención abierta a la interacción con los habitantes, con el entorno, y con los recursos disponibles que, con cierta informalidad, busca más allá de un resultado espacial una transformación

32 Trachana, 2013. en la actitud de las personas para buscar soluciones a sus necesidades y demandas.

\section{La experiencia ${ }^{33}$}

Las premisas para la actuación en el parque estaban relacionadas con: el involucramiento de los habitantes en el proceso de toma de decisiones de diseño; el uso de materiales de bajo costo que hicieran factible la replicabilidad futura por los habitantes y la sostenibilidad de la intervención; el uso de técnicas sencillas que facilitaran la transferencia del conocimiento a la comunidad; y la planificación de una acción posible de realizar dentro de los plazos propios del calendario académico. Por esta razón, se aplicaron algunos criterios de las metodologías descritas previamente para el desarrollo de la experiencia.

En este contexto, una de las primeras actividades realizadas para delimitar el trabajo consistió en definir quiénes participarían tanto desde el ámbito académico como comunitario. Así, por un lado, se articuló el trabajo con los colegas costarricenses quienes contaban con experiencia previa en trabajos de activación de espacio público y, por otro, con apoyo del programa Vidas Móviles se establecieron dos contactos claves con la comunidad. El

33 El equipo de trabajo manifiesta sus agradecimientos a la Pontificia Universidad Javeriana por el apoyo recibido para el desarrollo exitoso de la experiencia en campo. 
primero, con el presidente de la Junta de Acción Comunal del barrio quien, además de participar activamente de la actividad, informó sobre algunos grupos de habitantes que usaban cotidianamente el parque y que podían estar interesados en participar. Y el segundo, con el Centro Educativo Amigos de la Naturaleza CEAN, institución en donde reciben educación básica primaria niños y niñas entre 5 y 12 años, administrada por la Policía Nacional de Colombia y localizada en el predio adjunto al parque.

\section{EL PAROUE}

El área en donde se localiza el parque presenta una topografía inclinada con pendientes entre $15^{\circ}$ y $45^{\circ}$. Se presentan socavaciones producidas por erosión de la lluvia, bajando en dirección nortesur. El sector presenta zonas de alto riesgo por remoción en masa debido a la alteración de la cobertura vegetal, que usualmente protege el suelo, por el tránsito permanente y la falta de mantenimiento del mismo. Esto produce vulnerabilidad por la pérdida de elementos que componen el suelo ${ }^{34}$.
El predio del parque tiene un área total de 1.928 $\mathrm{m}^{2}$. El costado oriental colinda con edificaciones de uno a tres pisos construidas en ladrillo; varias de ellas poseen ventanas que dan al parque, pero ninguna tiene un acceso directo al mismo, desaprovechando la potencial articulación entre espacio privado y espacio público. De esta forma, la fachada hacia este costado se presenta como una gran culata sustentada en una zanja en la que usualmente se encuentra basura y material en descomposición dejado allí por los vecinos, lo que rompe definitivamente la continuidad funcional y espacial con el parque (foto 1). En el costado opuesto se localizan el salón comunal y la carrera 73 E. El salón comunal es una edificación de un piso, autoconstruida por los habitantes, cuya disposición funcional se niega también al parque, pero en cuya culata colindante se encontró el mural de un bosque pintado por la comunidad, aunque en avanzado estado de deterioro. En cuanto a la carrera 73 E, el tráfico vehicular solo puede circular en sentido norte-sur, debido a que presenta una pendiente pronunciada, y la circulación peatonal debe compartir espacio con los automóviles dada la ausencia de andenes.

34 Secretaria Distrital de Planeación, 2013. 
FOTO 1. VISTA COSTADO ORIENTAL DEL PAROUE

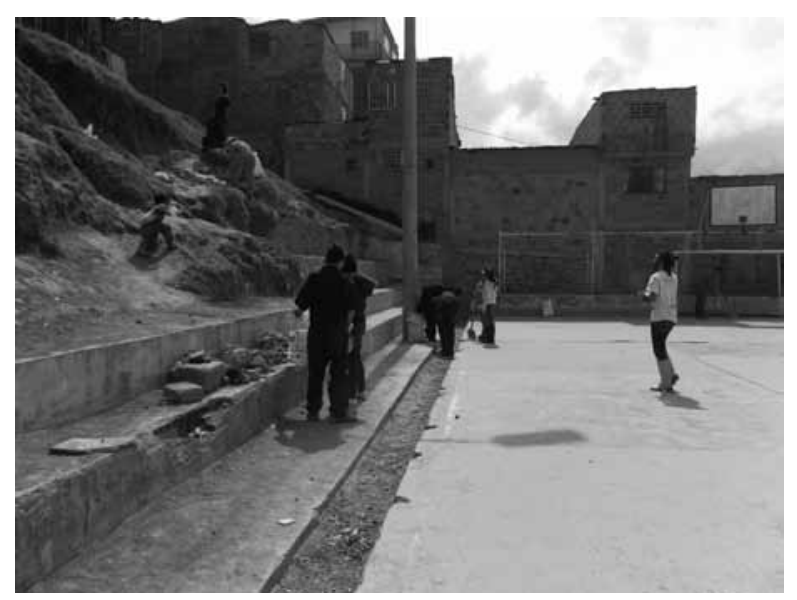

Fuente: autoras.

Sobre el costado norte, se halla la calle 76 A sur que separa al parque de edificaciones de uno y dos pisos con comercio barrial de bajo impacto. La vía es de doble sentido sin andenes o elementos que delimiten el área del parque. Así mismo, sobre el límite nor-occidental la comunidad tiene el hábito de depositar la basura y los desperdicios de construcción del sector, generando malos olores y contaminación visual (foto 2). El costado sur se encontraba delimitado por una barda de aproximadamente $50 \mathrm{cms}$ de altura, la cual tenía elementos de fijación para malla de cerramiento, pero sin la malla. Igualmente, hay un barranco en la misma
FOTO 2. VISTA COSTADO NORTE DEL PARQUE

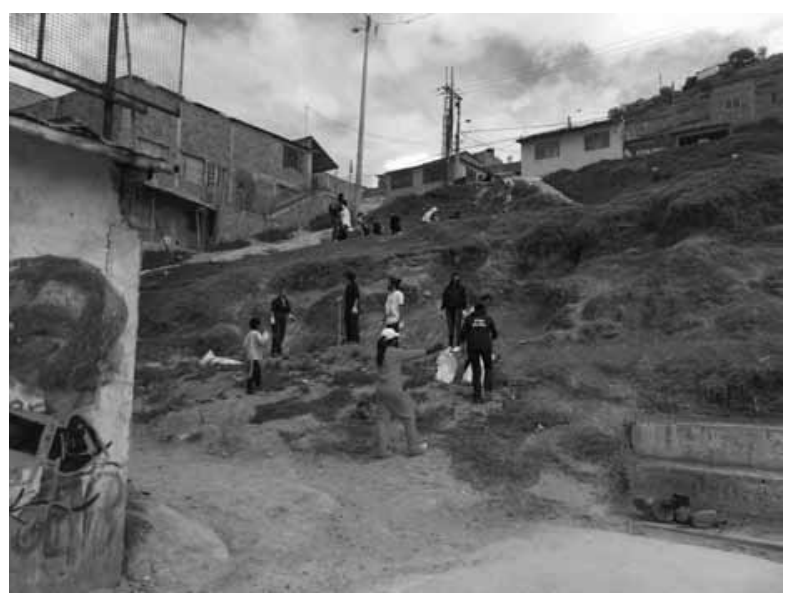

Fuente: autoras.

condición de desaseo y abandono que la zanja del costado oriental. Sobre este mismo costado el parque colinda con el CEAN. La edificación tiene una altura de un piso y se encuentra cerca de tres metros por debajo del nivel de la cancha múltiple que ocupa parte importante del área del parque.

Con respecto al acondicionamiento del parque en el momento de la intervención, además de la mencionada cancha, incluía un sector de juegos metálicos para niños. Sin embargo, en la cancha solo se encontró uno de los aros metálicos en los tableros de baloncesto y deterioro de las porterías para microfútbol, parte de los juegos infantiles estaba 
destruida y el resto deteriorada. Había abandono y escasez de material verde y luminarias deficientes. En conclusión, las características del parque no eran adecuadas para desempeñar la función para la cual fue construido.

\section{ZONIFICACIÓN}

A partir de las condiciones descritas, se planteó entonces diseñar y ejecutar un proyecto para la recuperación socio espacial del parque. Así, a partir de conversaciones preliminares con algunos de los miembros de la JAC se determinó conservar inicialmente las zonas de usos preestablecidos en el predio y trabajar sobre un área aproximada de $1100 \mathrm{~m}^{2}$ (figura 3). Las actividades para los jóvenes se mantuvieron en la parte baja del parque, en donde se encuentra la cancha múltiple, ya que sobre este sector están las graderías que permiten a los habitantes ser espectadores de los juegos que en ella ocurran y generar, además, actividades lúdicas y culturales en el mismo lugar. En la parte media se dejaron las actividades de niños, buscando que pudieran disfrutar de los juegos infantiles en un espacio independiente y resguardado de los riesgos del tráfico vehicular, reconociendo las ventajas ofrecidas por las condiciones topográficas.
Sobre la parte alta se conservó el aislamiento previsto sobre la calle $76 \mathrm{~A}$ sur que corresponde a una zona "verde" no edificable, sobre la que se proyectaba realizar una siembra de árboles para mejorar la contención del terreno y las condiciones ambientales del sector, logrando además elevar el indicador de árboles/habitante en la localidad que está en 0.1 , frente a otras como Usaquén que está en $0,25^{35}$.

\section{TALLERES CON LA COMUNIDAD}

En relación con la primera premisa de trabajo, se decidió realizar una serie de talleres con la comunidad, como ejercicio básico de diseño participativo que permitiera involucrarlos en el proceso de toma de decisiones sobre las acciones en su parque, en busca de la sostenibilidad de la intervención. Para ello, se convocó a la comunidad del barrio en general, a través de la Junta de Acción Comunal, y en particular a dos grupos identificados por los mismos habitantes como los principales usuarios del parque: los niños y jóvenes del CEAN ${ }^{36}$ quienes usan el parque para sus clases de educación física,

35 Bogotá tiene un árbol (...), 2007.

36 El apoyo del colegio fue fundamental tanto para la realización de los talleres como en la ejecución de las obras, al igual que con el préstamo de aulas del colegio para el desarrollo de las actividades. 


\section{FIGURA 3. ZONIFICACIÓN Y RELACIONES DE COLINDANCIA}

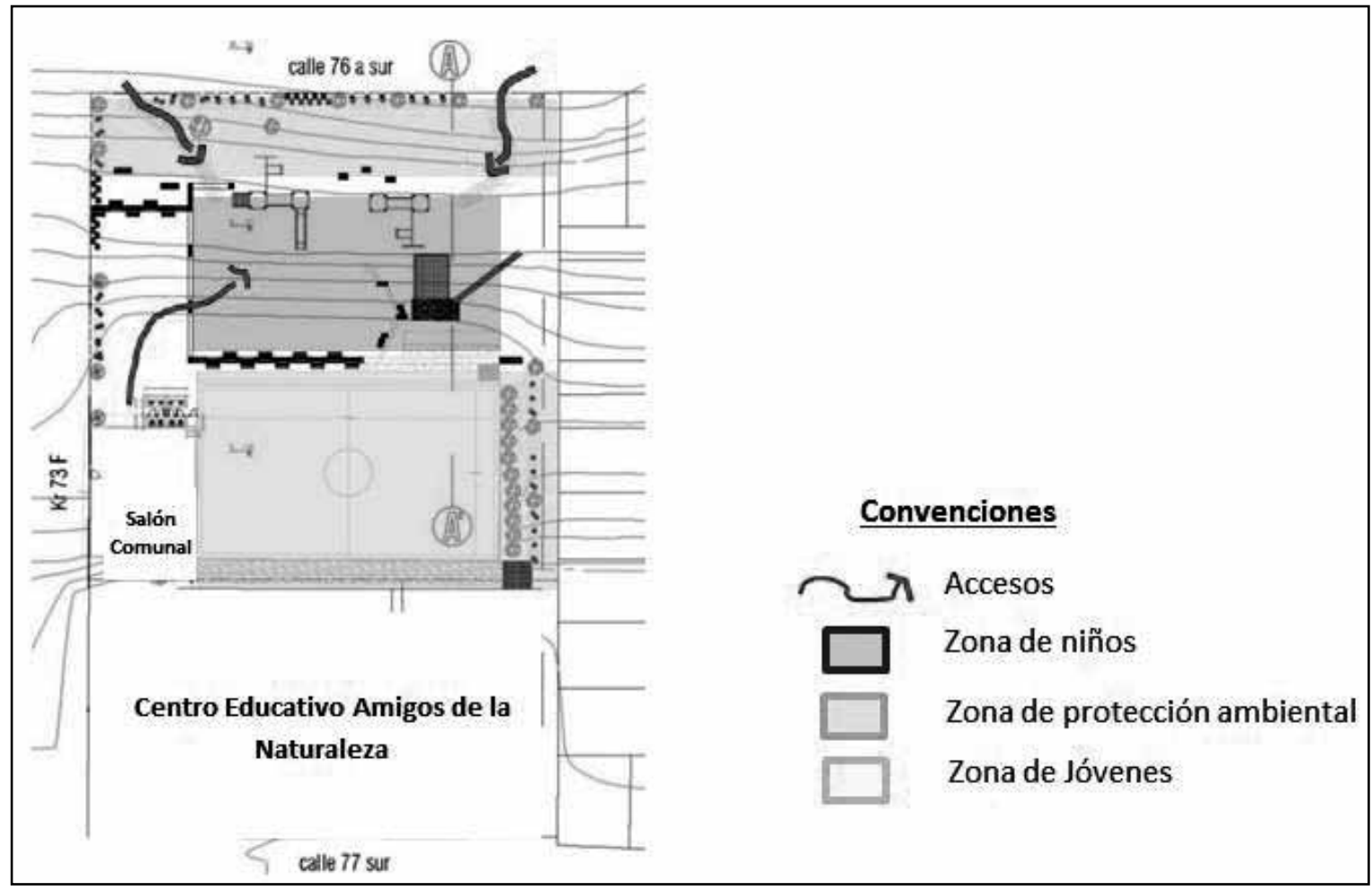

Fuente: elaboración propia a partir de estudiantes PVP 1330.

y un grupo de adultos mayores quienes lo usan para practicar deporte de manera regular.

El primero de los talleres tuvo por objetivo realizar un diagnóstico de la situación física y social en la que se encontraba el parque, y de las expectativas de la comunidad sobre este como espacio colectivo. El diseño del taller contempló dos fases: en la primera se indagó sobre la validez de la zonificación existente manifestada por miembros de la 
JAC, así como por el uso cotidiano del parque y la percepción de diversos lugares en su interior. En la segunda, se realizó un ejercicio de proyección de "sueños" (expectativas) sobre el mismo. Al respecto, se consideró importante diferenciar dichas percepciones y expectativas de acuerdo con el grupo de edad, propiciando la libre expresión de los niños. Para ello, se programó desarrollar el trabajo simultáneamente con un grupo de niños, otro con adultos y un tercero con el grupo de adultos mayores.

Aunque finalmente no se logró la participación del grupo de adultos mayores, si se desarrolló un trabajo diferenciado entre adultos y niños. Para ello, se recibió el importante apoyo del CEAN en el trabajo con niños, padres y profesores del grado cuarto de primaria, a través del área de ciencias naturales. Los principales resultados alcanzados fueron (foto 3):

Niños:

- El parque en general les gustaba con la zonificación y localización de los juegos porque es un espacio donde pueden jugar y eso los motiva, pero no les gustaba su deterioro físico, y les producían miedo las áreas de riesgo de accidentes, pues eran conscientes del peligro de lesión en determinados lugares del parque. Por ejemplo, los niños acostumbraban deslizarse por un tubo de aguas lluvias, abandonado, y soñaban con tener un elemento apropiado para este juego en el parque. Con respecto a las expectativas, se identificó que sus deseos estaban relacionados con el mejoramiento del mobiliario del parque y la aparición de elementos adicionales que les permitieran realizar actividades como deslizarse y trepar. Esto, en concordancia con las características topográficas del lugar.

\section{Adultos:}

- Expresaron su preocupación por algunas dificultades en el uso del parque por los diferentes grupos de edad, asociado a factores de seguridad y de dotación. No obstante, señalaron estar de acuerdo con la zonificación del parque y resaltaron su importancia como escenario para el desarrollo de actividades deportivas y recreativas que podían mejorarse con acciones sencillas y a su alcance.

El segundo taller consistió en la presentación de alternativas de diseño, desarrolladas por los estudiantes del PVP con base en los resultados del primer taller. A partir de la discusión sobre los resultados descritos, los estudiantes construyeron un programa de usos que debieron resolver a partir de materiales asequibles y de fácil instalación para los habitantes del barrio como: llantas usadas, botellas plásticas, canastas de bebidas, etc. Con base en estas condicionantes, se produjeron tres alternativas de diseño para el parque. Estas fueron presentadas 


\section{FOTO 3. PROCESO Y RESULTADOS TRABAJO CON NIÑOS}

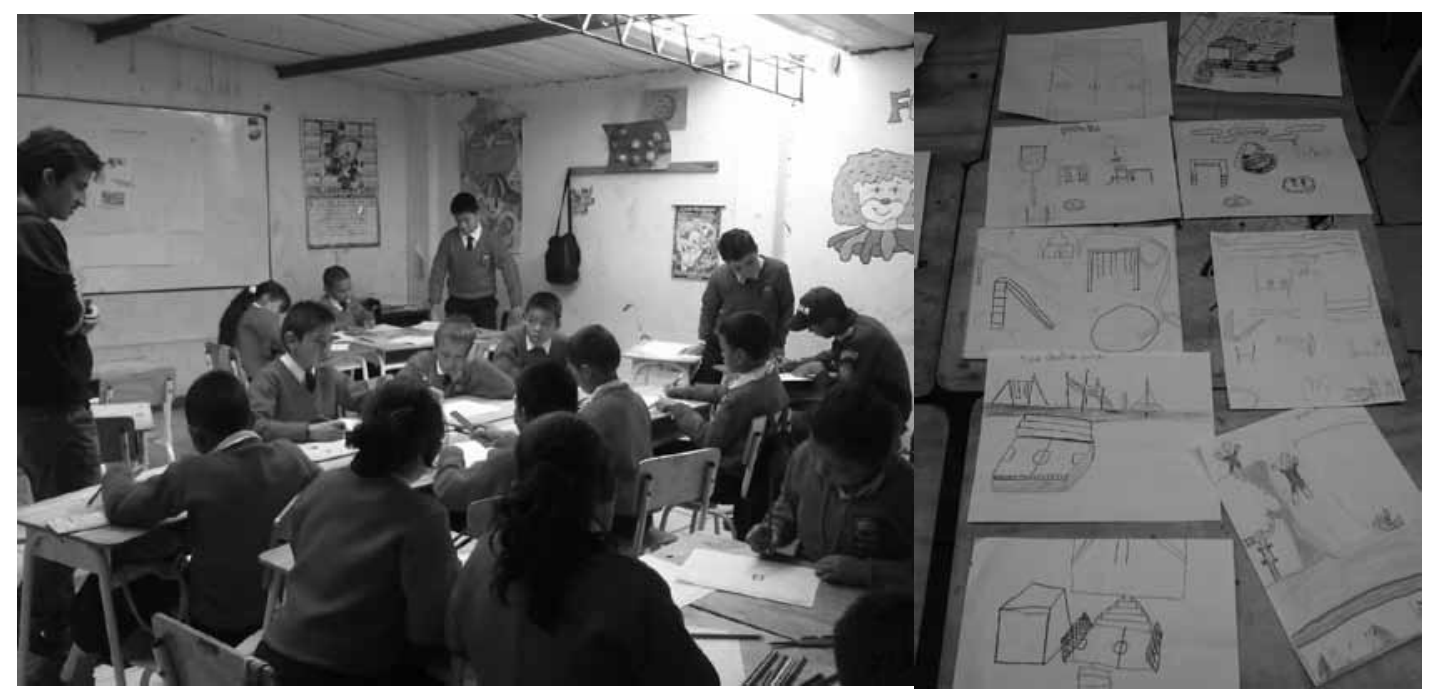

Fuente: autoras.

por los estudiantes, en una primera fase del taller, al grupo de adultos y niños en conjunto (foto 4). En la segunda fase, y con el objetivo de recoger las opiniones y preferencias sobre cada una de las alternativas presentadas, los participantes fueron divididos nuevamente por grupos de edad. La idea era descubrir los aspectos de cada propuesta más cercanos a lo que deseaban para su parque, obteniendo como principales resultados:

Niños:

- Se presentaron tres alternativas de diseño en planos y maqueta, mostrando opciones de acuerdo a los "sueños" que tenían para el lugar.
Se les pidió que, teniendo en cuenta la limitación de los recursos disponibles, seleccionaran tres elementos que de forma obligatoria debería contemplar el parque y tres opcionales. Se seleccionaron como prioridades la malla de escalar, el rodadero y la adecuación de juegos.

Adultos:

- Los adultos seleccionaron construcción de baños, la recuperación de áreas de juego y la construcción de escaleras.

Con dicha información, los estudiantes integraron en un solo diseño los aspectos identificados 
como importantes en el taller. Dicha propuesta integral fue presentada en el tercer y último taller en el cual, además, se explicó cómo sería la actividad de ejecución de obras desde el punto de vista organizativo. Allí, se explicó también que se iban a construir solo algunos de los elementos que incluía el diseño y que la intención era que a futuro los habitantes, como comunidad, continuaran la construcción del proyecto, iniciativa entendida y respaldada en ese momento por los asistentes.

Estos talleres fueron coordinados por profesores del PVP con apoyo de los estudiantes, quienes además incorporaron los resultados de los mismos como parte sus ejercicios académicos. Esto último, les permitió profundizar conocimientos sobre aspectos cualitativos asociados al proceso de habitar el barrio. Así mismo, en el desarrollo de las alternativas de diseño su creatividad se vio desafiada por condicionantes como: la confrontación entre las expectativas de los habitantes, las posibilidades técnicamente viables para el parque, las limitaciones en términos de costos y sus propias intenciones como diseñadores.

\section{GESTIÓN DE RECURSOS}

Paralelamente al desarrollo de talleres y diseños, el equipo de profesores responsables de la actividad se hizo cargo de adelantar gestiones para conseguir apoyo económico para la ejecución de las obras, lo que en gran medida determinó los elementos de diseño que finalmente pudieron ser construidos. Como resultado de esta actividad se logró contar con el apoyo de: Departamento de Arquitectura de la PUJ para compra de materiales y pago de auxiliar de obra; Programa Vidas Móviles, para alimentación durante la realización de los talleres y la ejecución de obras; Comunidad educativa grado cuarto del CEAN (profesores, padres de familia o apoderados y niños), con botellas plásticas rellenas con arena seca; Policía Nacional con transporte de materiales de donación; Dueño de taller mecánico del barrio con donación llantas usadas; Profesional independiente ${ }^{37}$ con asesoría técnico constructiva de las obras y donación de materiales. En total, los apoyos recibidos corresponden aproximadamente a una inversión equivalente a US $\$ 1.300^{38}$.

\section{EJECUCIÓN DE OBRAS}

A partir del diseño desarrollado por los estudiantes del PVP y con base en los materiales y recursos conseguidos, se determinaron elementos y

37 Se quiere hacer un agradecimiento especial al Ingeniero John Bernal por su apoyo y compromiso para el logro de la experiencia. 38 Según valor del dólar en Colombia el 22 de septiembre de 2015. 


\section{FOTO 4. PRESENTACIÓN ALTERNATIVAS DE DISEÑO}

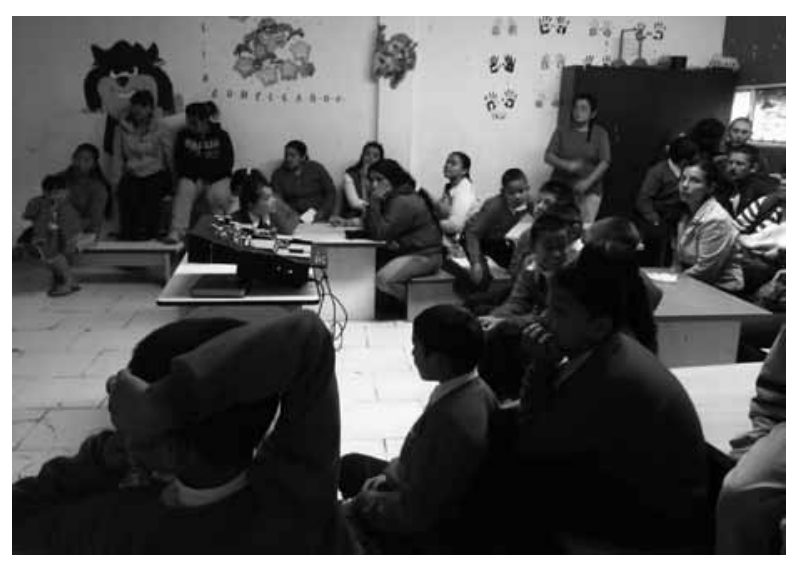

Fuente: autoras

acciones específicas a ejecutar en 4 días de trabajo, cuyos criterios de elección se sintetizan en la Tabla 1.

El trabajo en el parque se realizó entre el 23 y el 26 de septiembre de 2013. Fue organizado a partir de cuadrillas de trabajo, cada una de las cuales estaba conformada por estudiantes del PVP - PUJ, un estudiante o profesor de la UCR y miembros de la comunidad, con coordinación general de los profesores del PVP y del profesional independiente. La primera actividad realizada fue una limpieza general al parque, luego de lo cual se organizaron tres frentes de trabajo. El primero, se encargó de la construcción de las escaleras en senderos y las materas; el segundo, del mejoramiento de la cancha, la pintura exterior del salón comunal y la recuperación CON los niños del mural; el tercero se encargó del mantenimiento de los juegos infantiles y la construcción de la malla de escalar.

La construcción de la escalera se realizó en el sector noroccidental, lugar transitado por la comunidad que en épocas de lluvia representaba un problema por tratarse de suelo arcilloso. Allí, se niveló el terreno formando escalones sobre los que se instalaron llantas, anclándolas con varillas al suelo. El centro de cada llanta se llenó con escombro y se niveló con mortero. Las llantas fueron pintadas (foto 5).

Las materas se construyeron con botellas plásticas, rellenas previamente por la comunidad con tierra y escombro ${ }^{39}$. Estas, se enterraron formando círculos y se amarraron entre sí con manila plástica. El círculo central se llenó con tierra orgánica donde se sembraron plantas con flores y el exterior se reforzó con cemento (foto 6).

En cuanto a la zona infantil, para el mejoramiento de los juegos infantiles, en la construcción de la malla de escalar se usó manila plástica reciclada, que se trenzó e instaló sobre una base de columpios abandonada que sirvió como soporte. Para el trabajo en los juegos infantiles aún funcionales, se

39 Ruiz, López, Cortéz y Froese, 2012. 
contó con la acción conjunta entre comunidad y estudiantes, quienes lavaron, lijaron y pulieron, para luego aplicar una capa de pintura acrílica de diversos colores. Y finalmente, para la construcción del rodadero, se aprovechó la pendiente del terreno, se armó la base en cemento y ladrillo, que luego se esmaltó para facilidad de deslizamiento (foto 7).

En el salón comunal se realizó una pintura total de los muros exteriores, siendo necesario pañetar parte de uno de estos para dar un acabado parejo a las cuatro fachadas. Luego, sobre el muro que colinda con la multicancha y respetando el motivo original del mural que se encontró al iniciar la actividad, se pintó un nuevo mural de un bosque con ayuda de los niños del CEAN, algunas de sus madres y los estudiantes del PVP. Fue tal el entusiasmo con el que se desarrolló esta actividad que los dibujos de árboles se extendieron hasta la fachada norte del salón. La multicancha había perdido la demarcación de los juegos para su uso, por lo que se repintaron las líneas reglamentarias de microfútbol y baloncesto. Adicionalmente, se pintaron las mallas metálicas perimetrales y se instalaron los sectores faltantes con malla plástica, se construyeron y pintaron los muretes faltantes, se aplicó una capa de pintura a las gradas de las tribunas, y se instaló el aro faltante en el tablero de baloncesto (foto 8).

\section{Conclusiones}

La experiencia desarrollada permitió articular los resultados de investigaciones previas sobre asentamientos informales y espacio público, procesos de enseñanza-aprendizaje y trabajo con la comunidad, integrando criterios de metodologías participativas, en torno a un mismo propósito: desarrollar capacidades en los habitantes para actuar positivamente sobre su territorio, en particular sobre su espacio público, dando cumplimiento a los objetivos propuestos. Se buscaba aportar desde la academia a la reivindicación del derecho a la ciudad de comunidades vulnerables, generando un espacio de participación que movilizara a los habitantes del barrio Caracolí hacia nuevos procesos de mejoramiento de sus condiciones de vida liderados por ellos mismos. Y de igual forma, la experiencia se planteó como estrategia metodológica dentro del proceso formativo, a fin de involucrar a los estudiantes en el conocimiento del problema y en los alcances reales de las soluciones que desde el diseño arquitectónico se proponen.

\section{LO ACADÉMICO}

Esta actividad, en donde lo humano y lo técnico se unieron en una apuesta colectiva en beneficio de la comunidad, marcó una diferencia significativa en la experiencia formativa de los estudiantes. El 


\section{TABLA 1. CRITERIOS DE ELECCIÓN DE ACCIONES}

\begin{tabular}{|c|c|c|c|c|}
\hline ÁREA & DIFICULTADES & PERCEPCIÓN & ELEMENTOS & ACCIONES \\
\hline Social & $\begin{array}{l}\text { - Espacio para actividades } \\
\text { deportivas deteriorado. } \\
\text { - Espacio para juegos infantiles } \\
\text { inadecuado / peligroso. } \\
\text { - Manejo de basuras } \\
\text { inadecuado. }\end{array}$ & $\begin{array}{l}\text { Lugar peligroso / de } \\
\text { vicio. }\end{array}$ & - Mural. & $\begin{array}{l}\text { - Diseño participativo. } \\
\text { - Limpieza general par- } \\
\text { que y construcción CON } \\
\text { comunidad. } \\
\text { - Pintura de mural CON } \\
\text { niños. }\end{array}$ \\
\hline Físico Espacial & $\begin{array}{l}\text { - Malla perimetral multicancha } \\
\text { incompleta. } \\
\text { - Aro tablero de baloncesto } \\
\text { ausente. } \\
\text { - Demarcación de juegos multi- } \\
\text { cancha poco visible. } \\
\text { - Juegos infantiles } \\
\text { deteriorados. } \\
\text { - Muros salón comunal } \\
\text { deteriorados. } \\
\text { - Senderos pendientes sin } \\
\text { escalonamiento. }\end{array}$ & $\begin{array}{l}\text { Lugar deteriorado y } \\
\text { abandonado. }\end{array}$ & $\begin{array}{l}\text { - Escaleras en sen- } \\
\text { deros desde calle } \\
\text { 76A sur hasta la } \\
\text { multicancha. } \\
\text { - Juegos infantiles } \\
\text { - Muros exteriores } \\
\text { salón comunal. } \\
\text { - Multicancha. }\end{array}$ & $\begin{array}{l}\text { - Construcción escaleras. } \\
\text { - Pintura juegos infantiles. } \\
\text { - Construcción } \\
\text { escaladora. } \\
\text { - Construcción tobogán. } \\
\text { - Pañete y pintura muros } \\
\text { exteriores salón comunal. } \\
\text { - Complementación y pin- } \\
\text { tura total malla perimetral. } \\
\text { - Remarcación líneas } \\
\text { multicancha. } \\
\text { - Instalación aro } \\
\text { baloncesto. }\end{array}$ \\
\hline Ambiental & $\begin{array}{l}\text { - Escasez de vegetación. } \\
\text { - Topografía escarpada. }\end{array}$ & $\begin{array}{l}\text { Lugar sucio (tierra) / } \\
\text { peligroso para juego } \\
\text { de niños. }\end{array}$ & - Materas. & $\begin{array}{l}\text { - Construcción materas. } \\
\text { - Sembrado de plantas } \\
\text { florales. }\end{array}$ \\
\hline
\end{tabular}

Fuente: elaboración propia. 


\section{FOTO 5. CONSTRUCCIÓN DE ESCALERAS}

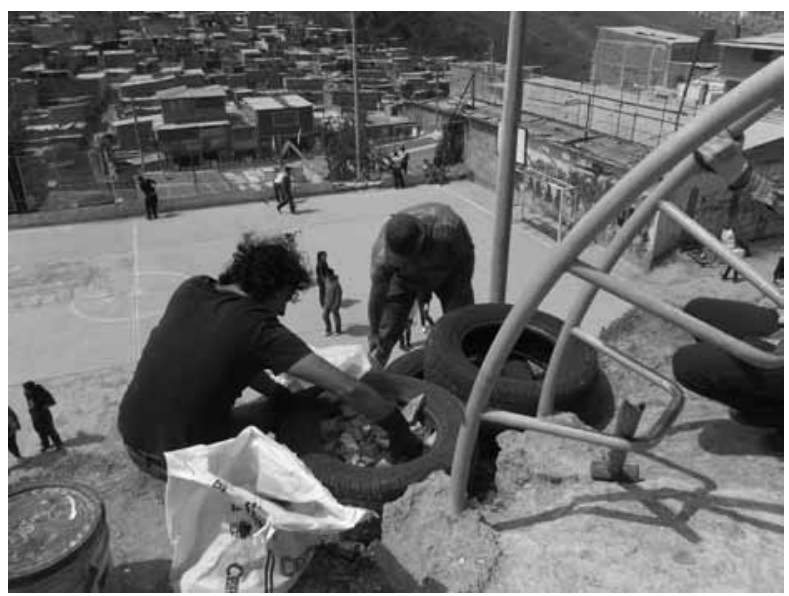

Fuente: autoras

conocimiento de la realidad desde el aula y sobre datos fríos, contrastado con el diálogo y el trabajo en el lugar donde vive la gente, habitando con ellos ese espacio en donde construyen sus vidas, enriqueció la reflexión y transformó la mirada sobre la ciudad informal y sus potencialidades. En espacios de diálogo en torno a lo realizado, los estudiantes manifestaron que más allá del gran esfuerzo físico y la inversión de tiempo que significó para ellos participar en la actividad, lograron comprender

\section{FOTO 6. CONSTRUCCIÓN DE MATERAS}

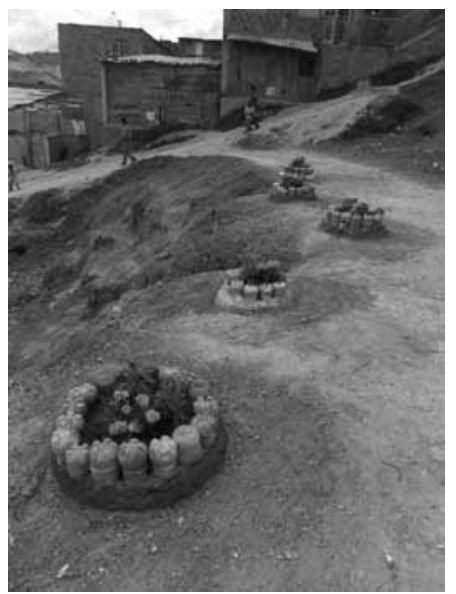

Fuente: autoras

mejor lo que significa habitar un barrio informal, pudiendo además verificar en la práctica conocimientos asociados con lo que implica la construcción y gestión de lo que diseñan. Por su parte, para el equipo de profesores significó una excelente oportunidad, tanto para fortalecer procesos pedagógicos como para articular la actividad docente con labores de servicio, que permiten actuar frente a una realidad que requiere ir más allá de la observación y el análisis. En este contexto, en los semestres siguientes, dentro de la misma asignatura, se 
FOTO 7. CONSTRUCCIÓN Y MEJORAMIENTO JUEGOS INFANTILES

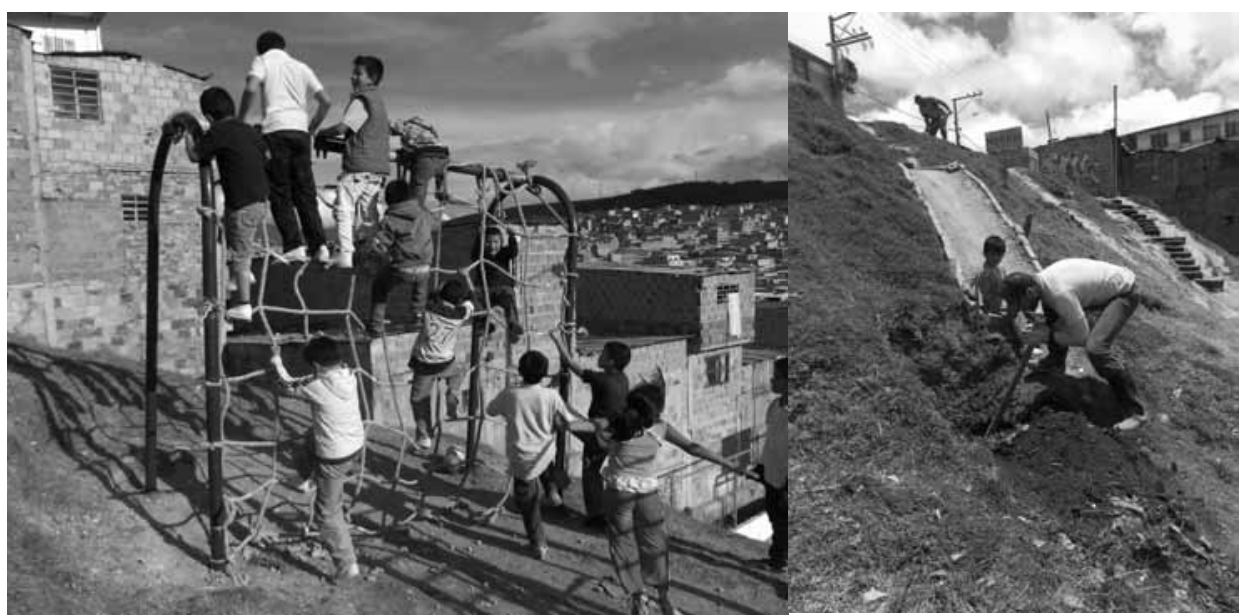

Fuente: autoras

FOTO 8. MEJORAMIENTO ÁREA MULTICANCHA

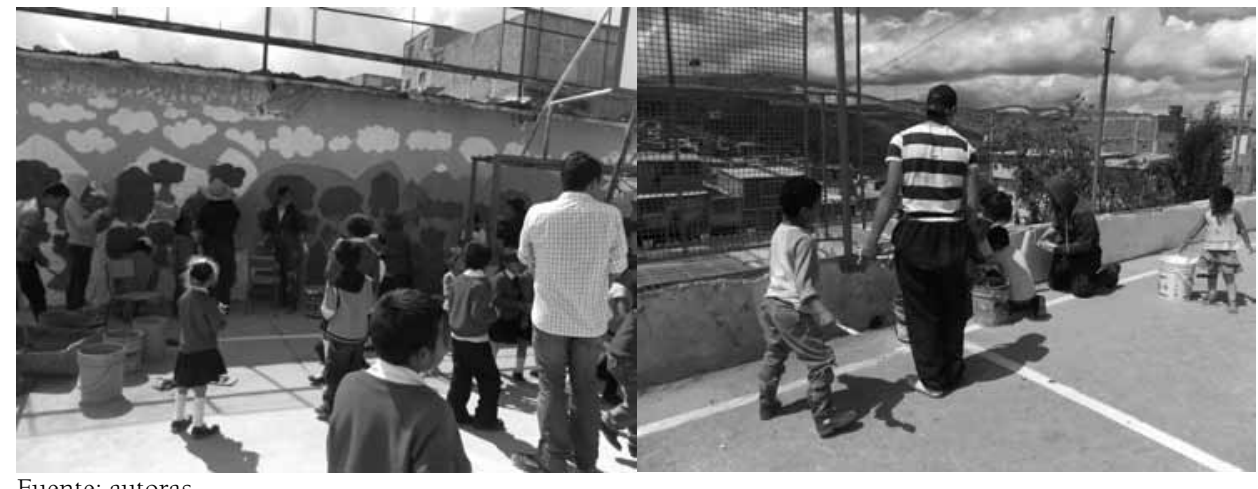

Fuente: autoras 
han realizado ejercicios tanto en espacio público como en el análisis de las condiciones de habitabilidad de la vivienda y recomendaciones para su mejoramiento, lo cual ha permitido continuar la interacción con la comunidad, en una relación de intercambio de saberes.

\section{LA COMUNIDAD}

Aunque se trató de una acción modesta, se logró impactar positivamente en quienes apoyaron y se beneficiaron del cambio. Según manifestaron en ese momento, para quienes participaron fue un momento feliz al sentirse reconocidos y descubrir sus propias capacidades para transformar su realidad, con lo cual la hipótesis quedó demostrada. Además, más allá de la emotividad del momento, lo más importante han sido los impactos generados con esta experiencia:

"(...) con la intervención que se hizo el año pasado el alcalde vino a pararnos bolas con el tema del parque, era que ese tema estaba dormido allá... inclusive en una vez estuvimos hablando con el alcalde allí como en una charla formal y dijo(...) Ud. me intervino el parque, y le dije: unos arquitectos que nos ayudaron allá de la Universidad Javeriana, iy quién dio orden?, pues ellos llegaron presentaron el proyecto(...) la comunidad aceptó una parte(...) en una reunión y aceptaron(...).

(...) digamos que el trabajo que nosotros hicimos fue un trabajo, primero porque lo hicimos de voluntad, si, con la colaboración de ustedes que es un agradecimiento inmenso por parte de la Junta de Acción Comunal para ustedes... fue una intervención, digámoslo a medias, cierto? pero esa intervención trajo una cosa más positiva todavía de lo que hicimos, sí, porque para nosotros eso fue positivo pero de ahí pa'ca vino algo más positivo que fue ya la intervención del parque ya a través de la alcaldía local"40.

En 2014 la alcaldía local de Ciudad Bolívar realizó un trabajo de mejoramiento sobre el parque, que aunque no fue mucho más allá de la intervención aquí presentada ${ }^{41}$, si fue muy significativo para la comunidad pues se trató de una acción estatal que por lo demás ha estado vinculada con otras más en torno al mejoramiento del barrio. Así mismo, durante este tiempo dos colectivos urbanos han hecho contacto con la comunidad y están liderando acciones en relación con el parque. Uno de

40 Agustín Chacón, entrevistado por Olga Ceballos y Cecilia López, 2 de octubre 2014, Bogotá.

41 Este trabajo consistió en: limpieza general del predio; obras de contención del terreno entre el CEAN y el parque; reconstrucción de loza, cambio de malla perimetral y de arcos y tableros de la multicancha; readecuación de juegos infantiles con instalación de baranda que mejora las condiciones de seguridad de los niños y reemplazo de escalera de llantas por una en concreto.

ARTíCULO: Espacio público, periferia urbana y derecho a la ciudad. Intervención Parque Caracolí, Ciudad Bolívar/Sandra Caquimbo Salazar, Olga Lucía Ceballos Ramos, Cecilia López Pérez 
ellos, UrbanaMente, está trabajando en torno a la construcción de un nuevo Salón Comunal. Para ello, contrató con la Junta de Acción Comunal el diseño, a partir de las ideas desarrolladas por los estudiantes del PVP en un ejercicio el diseño participativo realizado en 2014 , el trámite para la licencia de construcción y el seguimiento de obra.

"ahí hay posible una biblioteca, una sala múltiple para internet (...), va a haber lo que es el salón múltiple que va a ser el de las asambleas, si, y el resto arriba va ser lo que es la oficina, y lo que va a haber salas y va a haber biblioteca, y de pronto, de pronto vamos a mirar a ver si es posible para hacer taller con los abuelos" ${ }^{\prime \prime 2}$.

El otro, es el mismo colectivo costarricense PAUSA URBANA, que ha continuado su trabajo en el barrio, ahora con una iniciativa de huertas urbanas en el área localizada entre el parque y el CEAN.

En cuanto al manejo de los productos de las huertas, al preguntar si se consideraba distribuirlos o venderlos, el presidente de la JAC manifestó:

"Sí, o se venden o se distribuyen para la gente que lo necesite. Al principio me imagino que será para consumirlos y ya a lo que ya haiga/ (SIC) una productividad que, más alta pues se puede vender allá en la plaza en Tres Esquinas, aquí hay Fruver (...)

42 Agustín Chacón, entrevistado por Olga Ceballos y Sandra Caquimbo, 30 de abril 2015, Bogotá. que bueno sería ¿no? Ojalá Dios quiera que nos dé esa, esa oportunidad de ver crecer nuestras matas" ${ }^{\text {"43 }}$.

Este movimiento social que se ha suscitado en el espacio del parque de Caracolí también se ha visto reflejado en la cotidianidad, a través de prácticas e iniciativas que han ido apareciendo con el paso del tiempo:

"la idea de encerrar es que quede bajo una protección y que se abra a un horario (...) y se cierre tipo 10 de la noche (...) la idea no es que no sea público, pero que si se pueda cerrar a un horario" ${ }^{\text {"44 }}$

"En el parque ha habido actividades por parte de las iglesias cristianas, se hizo un arreglo de servicios por parte de la Secretaría de Gobierno (...), también se hizo el cumpleaños de Caracolin"45

"sí, la idea es hacer una, una escuela de formación deportiva, sí, y también bregar a hacer un campeonato y bregar a sacar un equipo para intercalar con las ligas de los otros barrios. Porque casi Caracolí no ha participado en eso (...) Ya ahorita habiendo el parque y estamos buscando con un señor que se llama don Jesús Pinzón a ver quién, con quien nos podemos buscar apoyo para ese, pues al menos como pa' los uniformes, pa' todo eso"w6.

43 Ibíd

44 Agustín Chacón entrevistado por Olga Ceballos y Cecilia López, 2 de octubre 2014, Bogotá.

45 Ibíd.

46 Ibíd 
Al preguntar si además de esta iniciativa de la JAC, los jóvenes estaban promoviendo otras actividades, el presidente indicó:

"Sí, hay algún grupo, que hablan con uno, no vienen a las reuniones y vienen y lo buscan a uno, me reuní con un grupo como de 15 que quieren formar un equipo para hacer un campeonato (...) un campeonato interbarrial ${ }^{147}$.

Todas estas acciones en torno al parque muestran cómo a partir de una pequeña experiencia que involucró a la comunidad, se puede impulsar una presencia más activa de los habitantes en la transformación del territorio, devolviendo la confianza en sus capacidades colectivas y fortaleciendo procesos de arraigo que seguramente contribuirán a alcanzar condiciones de bienestar en los espacios habitacionales de estos barrios.

\section{METODOLOGÍAS PARTICIPATIVAS}

En cuanto a la aplicación de criterios de metodologías participativas, se comprobó que son válidos para empoderar y motivar una comunidad frente a las dificultades y limitaciones de desarrollo del espacio público; así como para asegurar la sustentabilidad de un proyecto a través de la apropiación colectiva. Igualmente, se corroboraron algunos aspectos propios de las metodologías contempladas:

47 Ibíd.

140 revista invi 32(89) : 113-143, mayo 2017 a) generar un cambio positivo dentro de la comunidad, en este caso frente al espacio colectivo; b) fomentar la participación y autogestión de la comunidad; c) evidenciar que es posible relacionar el conocimiento académico y la participación de la comunidad en un ámbito real. Estos factores conllevaron a que se replanteara la forma tradicional de docencia en arquitectura, constituyéndose en un proceso compartido entre la Universidad y la comunidad, en donde se descubrieron, entendieron y analizaron las diferentes variables que afectan las áreas públicas en sectores con población vulnerable, teniendo como propósito principal el mejoramiento y calidad del espacio público.

\section{Bibliografía}

ACERO CABALLERO, Guillermo; AGUIRRE SUCH, Jon; ARÉVALO MARTÍN, Jorge; DÍAZ RODRÍGUEZ, Pilar y ROMERO FERNÁNDEZ DE LARREA, Iñaki. A participar se aprende participando. VdB: Acción y reflexión críticas en el proyecto para la regeneración urbana participativa en el barrio Virgen de Begoña (Madrid). [En línea]. Hábitat y Sociedad. (4): 15-31, 2012. Disponible en: http://www.habitatysociedad.us.es/index.php?option=com_con tent\&view $=$ article $\& i d=52 \&$ Itemid $=5$.

BOCANEGRA OCHOA, Ricardo. No estoy solo me sumo a la convivencia y desisto de la violencia. Universidad Santo Tomás. 2015. 
BOGOTÁ tiene un árbol por cada siete habitantes; la regla internacional es uno por cada tres. [En línea]. El Tiempo. 26 noviembre 2007. Disponible en http://www.eltiempo.com/archivo/documento/ CMS-3833721.

CAQUIMBO SALAZAR, Sandra. La calidad del espacio público en la construcción del paisaje urbano. En busca de un hábitat equitativo. Revista INVI. 23(62): 75-97, mayo 2008. ISSN e0718-8358.

CEBALLOS RAMOS, Olga. La cualificación de la periferia urbana y el espacio público. Una reflexión desde las políticas públicas de Bogotá. [En línea]. Revista Territorios. (18-19): 207-227, 2008. ISSN 0123-8418. Disponible en: http://revistas. urosario.edu.co/index.php/territorios/article/ view/833/753.

CEBALLOS RAMOS, Olga; CAICEDO MEDINA, Julián; FERNÁNDEZ JUAN, Amelia; RINCÓN CASTELLANOS, Milena. Salubridad de la vivienda informal. En: BARRAGÁN MONTAÑA, Andrés. El traspatio de la ciudad. Desafíos, prácticas y recomendaciones de política pública y de capacitación frente a la vivienda informal. Bogotá, Swisscontact, Fundación Suiza de Cooperación para el Desarrollo Técnico. 2014. p. 48-74. ISBN 978-958-8575-62-9.
CEBALLOS RAMOS, Olga; VEGA ROMERO, Román; FERNÁNDEZ JUAN, Amelia; MARTÍNEZ COLLANTES, Jorge; FERNEY HERRERA, Ronald; LONDOÑO PALACIO, OIga; CHAPARRO BORJA, Paola; CAICEDO MEDINA, Julián; RINCÓN CASTELLANOS, Milena y GIRALDO VILLATE, Claudia. La habitabilidad y la salud en Colombia. Una propuesta metodológica para su análisis. Bitácora Urbano Territorial. 25(1): 31-41, enero 2015. ISSN 2027-145X. DOI 10.15446/bitacora.vln25.44011.

CODHES Consultoría para los Derechos Humanos y el Desplazamiento. Sistema de información número de personas desplazadas por municipio por año. [En línea]. COHDES. s.f. Disponible en: http://www.codhes.org/index. php?option=com_si\&type $=1$.

DUARTE BERNAL, Diana; SALINAS ROJAS, Marcelo; CORNEJO, Daniela; OLAVE J., Cynthia y KATZ, Daniel. Modelos de desarrollo cultural para el espacio público: ciudadanía y participación creativa. Santiago, Consejo Nacional de la Cultura y las Artes. 2013.

GREENW00D, Davydd J. De la observación a la investigación-acción participativa: una visión crítica de las prácticas antropológicas. Revista de Antropología Social. (9): 27-49, 2000. 
HERNÁNDEZ GARCÍA, Jaime. Construcción social de espacio público en barrios populares de Bogotá. Revista INVI. 28(78): 143-178, 2013. DOI 10.4067/S0718-83582013000200005.

Arquitectura, participación y hábitat popular. Bogotá, Editorial Pontificia Universidad Javeriana. 2008.

JARAMILLO, Jaime. Cultura, espacio público y uso del tiempo libre. Localidad 18 Rafael Uribe, Santa Fe de Bogotá. Bogotá, Instituto Distrital de Cultura y Turismo, Observatorio de Cultura Urbana. 1998.

MARTIN-IGLESIAS, Rodrigo. Hacia un nuevo paradigma de diseño colaborativo. En: Congreso Iberoamericano de Gráfica Digital (15², 2011, Santa $\mathrm{Fe})$.

MUJERES y género en América Latina. [En línea]. Freie Universität Berlin Instituto de Estudios Latinoamericanos. [Fecha de consulta: 30 junio 2016]. Disponible en: http://www.lai.fu-berlin.de/es/e-learning/projekte/frauen_konzepte/projektseiten/ index.html.

NIÑO, Carlos y CHAPARR0, Jairo. El espacio público en algunos barrios populares de la Bogotá actual. En: La calle: lo ajeno, lo público y lo imaginado. Bogotá, Barrio Taller. 1997. p. 98-103.

OBRAS con saldo pedagógico (Colombia). [En línea]. Ciudades para un Futuro más Sostenible. Julio 2000. [Fecha de consulta: 30 junio 2016]. Disponible en: http://habitat.aq.upm.es/bpal/onu00/bp545. html.

142 revista invi 32(89) : 113-143, mayo 2017
ORTIZ, Marielsa y BORJAS, Beatriz. La investigación acción participativa: aporte de Fals Borda a la educación popular. Espacio Abierto Cuaderno Venezolano de Sociología. 17(4): 615-627, 2008. ISSN 1315-0006.

RUIZ VALENCIA, Daniel; LÓPEZ PÉREZ, Cecilia; CORTES, Eliana y FROESE, Andreas. Nuevas alternativas en la construcción: botellas PET con relleno de tierra. Apuntes. 25(2): 292-303, 2012.

SECRETARIA Distrital de Planeación; Dirección de Ambiente y Ruralidad y Dirección de Legalización de Barrios. Plan de mejoramiento urbanístico Altos de la Estancia. [En línea]. Secretaría Distrital de Planeación. 2013. Disponible en http://www.sdp. gov.co/portal/page/portal/PortalSDP/SeguimientoPoliticas/politicaRuralidad/MetasPlanDesarrollo/Plan_de_Mejoramiento_Urbanistico_AltosEstancia_CR07-04-.pdf

TARCHÓPULOS Doris y CEBALLOS, Olga. Patrones urbanísticos y arquitectónicos en la vivienda dirigida a los sectores de bajos ingresos en Bogotá. Bogotá, Centro Editorial Javeriano. 2005.

Calidad de la vivienda dirigida a los sectores de bajos ingresos en Bogotá. Bogotá, Centro Editorial Javeriano. 2003.

TORRES, Carlos, coord. Ciudad informal colombiana. Barrios construidos por la gente. Bogotá, Universidad Nacional de Colombia. 2009.

TRACHANA, Angelique. Procesos emergentes de transformación del espacio público. Bitácora Urbano Territorial. 1(22: 43-52, 2013. 
VARISCO, Cristina; BENSENY, Graciela; CASTELLUCCI, Daniela; GONZÁLEZ, María Graciela; PADILLA, Noelia; MUÑOZ, María Julia y CÉSAR, Cristian. La extensión universitaria como forma de implementar la investigación-acción participativa. VII Simposio Internacional y XIII Jornadas Nacionales de Investigación-Acción en Turismo CONDET. Congreso Internacional de Turismo ANET Facultad de Turismo UNCo, Neuquén. 2015. 